\title{
"QUANDO O DINHEIRO ENTRA NA TRIBO": A MONETARIZAÇÃO DA VIDA PAITER SURUí (1969-1990)
}

\author{
"WHEN MONEY ENTERS THE TRIBE": THE \\ MONETIZATION OF LIFE PAITER SURUÍ \\ (1969-1990)
}

Carlos Alexandre Barros Trubiliano*

Bruno Surui ${ }^{* *}$

Resumo: O artigo que segue partiu da hipótese de que o avanço da economia madeireira, no território rondoniense, provocou a monetarização da vida dos Paiter Suruí, cuja principal alteração se deu na produção e reprodução da vida material: se antes havia um forte sentido comunal e de coletividade, esse processo passou a ser intermediado pela lógica monetária, acumulatória e individual. O objetivo geral deste estudo foi identificar as transformações na vida dos Paiter Suruí após a monetarização das relações sociais. Especificamente: a investigação buscou historicizar as mudanças e apontar os impactos sociais causados pela lógica monetária na vida dos Paiter Suruí. Como suporte teórico a pesquisa utilizou entre outros teóricos, Georg Simmel, para qual a economia do dinheiro é que determina as relações sociais na modernidade. Para o filosofo alemão nas sociedades pré-monetárias, o indivíduo depende diretamente da coletividade para sua existência, após a monetarização os indivíduos passam a exercer cada vez mais o individualismo, marcado por uma lógica relacional de compra e venda do tempo, das relações sociais e do trabalho.

\footnotetext{
Doutor em História (UNESP/Franca). Docente do Curso de Licenciatura Intercultural da Universidade Federal de Rondônia (UNIR).

${ }^{* *}$ Educador, agricultor familiar e graduado em Licenciatura Intercultural na Universidade Federal de Rondônia (UNIR).
} 
Palavras-chave: Monetarização; Modernização; Paiter Suruí.

\begin{abstract}
The article that follows started from the hypothesis that the advancement of the timber economy, in the territory of Rondonia, caused the monetization of the life of the Paiter Surui, whose main change occurred in the production and reproduction of material life: if before there was a strong sense of communal and collectively, this process started to be intermediated by the monetary, accumulative and individual logic. The general objective of this study was to identify the transformations in the lives of Paiter Surui after the monetization of social relations. Specifically: the investigation sought to historicize the changes and point out the social impacts caused by the monetary logic in the lives of the Paiter Suruí. As theoretical support, the research used, among other theorists, Georg Simmel, for whom the economy of money determines social relations in modern times. For the German philosopher in pre-monetary societies, the individual depends directly on the collectivity for his existence, after monetization, individuals begin to exercise more and more individualism, marked by a relational logic of buying and selling time, social relations and of work.
\end{abstract}

Keywords: Monetarization; Modernization; Paiter Suruí.

\title{
Introdução
}

Suruí foi a denominação dada pelos primeiros sertanistas, responsáveis pelo contato oficial, ao povo indígena que se autodenomina Paiter - que, numa tradução livre para o português, significa "nós mesmos" ou "gente de verdade". A população Paiter Suruí é organizada em quatro divisões clânicas patrilineares, cujas linhagens são Gabgir, Gamir, Makór e Kaban; esta última descende de uma fusão com o povo Cinta Larga.

O maior contingente populacional Paiter Suruí - 215 famílias reside na Terra Indígena Sete de Setembro, cuja extensão territorial é de aproximadamente 250 mil hectares, localizada entre os estados de Rondônia e Mato Grosso. De acordo com os dados da Casa de Apoio à Saúde do Índio (CASAI, 2018), existem 26 aldeias distribuídas ao longo 
de toda a Terra Indígena. Embora $60 \%$ desta área esteja no território mato-grossense (aproximadamente $147 \mathrm{mil} \mathrm{ha),} \mathrm{apenas} \mathrm{quatro} \mathrm{aldeias}$ estão no MT; em termos populacionais, isso representa menos de $10 \%$. A maior parte da população Paiter Suruí está em Rondônia, o que nos permite afirmar que a maioria das relações, sejam comerciais, políticas ou econômicas, dá-se no estado de Rondônia, especialmente no município de Cacoal.

O contato Paiter Suruí com os não índios foi iniciado na década de 1960; esse período foi marcado por altas taxas de mortalidade em decorrência de doenças até então desconhecidas pelos indígenas, principalmente o sarampo (ISA, 2003). A história do povo Paiter Suruí pós-contato relaciona-se diretamente com as políticas de ocupação espacial de Rondônia. O território rondoniense, ao contrário do discurso oficial de que era uma "terra sem homens" destinada a "homens sem terras", não era um "imenso espaço vazio".

Partindo dos estudos de Becker (1991), o avanço colonizatório de Rondônia (considerado, nessa pesquisa, como uma etapa do desenvolvimento do capitalismo) alicerçou-se em duas políticas, a saber: 1) a construção da rodovia BR-364, na década de 1970; 2) os programas de assentamento populacional, como os Projetos de Assentamento Dirigido (PADs), os Projetos Integrados de Colonização (PICs) e os Projetos de Assentamento Rápido (PARs). Ambos os instrumentos permitiram canalizar o fluxo de trabalhadores sem terra e/ou desempregados da região Centro-Sul do país para a fronteira rondoniense. Ainda segundo Becker, os fluxos migratórios foram além dos assentados: com a assistência do Estado, registrou-se também um grande contingente que migrou espontaneamente e se fixou por conta própria, orientando-se pelo modelo oficial - assentando-se, porém, de maneira litigiosa. Deste modo, o fluxo populacional que migrou para Rondônia excedeu a capacidade de controle dos órgãos oficiais (BECKER, 1991).

Diante do exposto, em pouco mais de 30 anos, a população de Rondônia passou de aproximadamente 40 mil habitantes, em 1950, a quase 900 mil habitantes em 1984. O notório crescimento populacional, aliado à incapacidade dos órgãos oficiais de organizar as frentes migratórias, culminou em processos de ocupações e invasões, acirrando os 
conflitos entre os colonizadores e os povos tradicionais (BECKER, 1991).

A expansão das fronteiras econômicas, marcada por conflitos, provocou mudanças nas comunidades indígenas. No caso dos Paiter Suruí, a abertura do PIC Gy-Paraná (1972) e os seus desdobramentos, como o avanço da economia madeireira, fizeram com que os Paiter Suruí estabelecessem uma nova lógica econômica.

Esse projeto de pesquisa partiu da hipótese de que o avanço da economia madeireira provocou a monetarização da vida dos Paiter Suruí, cuja principal alteração se deu na produção e reprodução da vida material: se antes havia um forte sentido comunal e de coletividade, esse processo passou a ser intermediado pela lógica monetária, acumulatória e individual.

\section{Trabalho e cosmologia}

Para pensarmos sobre a produção e reprodução material dos Paiter Suruí antes do contato, é preciso manter no horizonte que, para as sociedades indígenas, de modo geral, uma única atividade coletiva e produtiva pode desempenhar diversos papéis e funções ao mesmo tempo, sejam eles religiosos, econômicos, politicos, sociais ou culturais. Essa observação é fundamental para introduzir a temática das relações econômicas indígenas pré-capitalistas dos Paiter Suruí.

O filósofo Friedrich Engels, ao pensar sobre a função social do trabalho, ressaltou que, para além da produção material - ou seja, a "fonte de toda riqueza" -, o trabalho se tornou a "condição básica e fundamental de toda a vida humana". Em outros termos, as relações estabelecidas pelo e com o trabalho nos permitem compreender as formas como a sociedade se organiza "tal grau que, até certo ponto, podemos afirmar que o trabalho criou o próprio homem" (ENGELS, 1977, p. 63).

Na perspectiva marxista, o trabalho, em qualquer modelo social, não é mero fruto de ação individual: ele repercute e é resultado de ações sociais, sejam elas decorrentes do acúmulo de práticas e conhecimentos, da produção e reprodução da cultura material e do capital cultural. O 
trabalho é, portanto, a expressão do grupo, da manutenção ou - em caso de rupturas - das transformações das formas de organização política, social e econômica (MARX, 1991).

Na sociedade contemporânea ocidental, atividades aparentemente desconexas como construir uma rodovia, postar uma selfie no Facebook, ir a um culto neopentecostal no domingo, erguer um parque industrial ou tomar um sorvete no Bob's carregam em si a produção e reprodução das sociedades que as geraram. De modo semelhante, quando pensamos nas sociedades indígenas, especialmente as pré-capitalistas, atividades como fazer uma flecha, pintar o corpo, preparar o roçado e conversar com os espíritos da floresta são resultantes de uma produção social e que, ao mesmo tempo, garantem as sociabilidades, estabelecem relações de pertencimento e de sobrevivência material.

Quando tratamos das atividades produtivas dos Paiter Suruí, especialmente no período pré-capitalista, é possivel identificar elementos convergentes entre religião, trabalho e diversão; exemplo disso são as festas tradicionais. De maneira convergente, celebrações - como a festa Gamanré, que serve como preparo da roça; o Lawaãwewa, dedicado à celebração e à construção de moradias; o Ytxaga, ritual para pesca com timbó; ou o Mapimai, que celebra a criação do mundo dentro da cosmologia Paiter - organizam as atividades produtivas, são mecanismos de interação social e de intersecção espiritual. Tomemos esse último (ritual Mapimẩ) como exemplo para compreendermos o cruzamento entre divisão social do trabalho, religião e organização social na cultura tradicional Paiter pré-capitalista.

O ritual Mapimaí - ou da criação do mundo - parte de uma cosmovisão em que se busca o equilíbrio e a reconciliação entre os seres humanos e as forças da natureza. Politicamente, o evento reforça os laços de aliança entre os clãs, buscando a unidade e o fortalecimento étnico. Ritualisticamente, o Mapimaí busca explicar a origem do mundo e como a sociedade Paiter se organiza. Todo o rito do Mapimaí é composto por uma complexidade de ações.

Para compreender o Mapimaí e a própria organização social dos Paiter, é preciso lembrar que existe a divisão clânica da etnia, composta pelos clãs Gameb (marimbondos pretos), Gamir (marimbondos 
amarelos), Makór (uma espécie de bambu amazônico) e Kaban (fruta regional). Tradicionalmente, ao longo de um ciclo anual, metade dos clãs fica ligada ao metare (floresta ou mato), responsável pela caça, e a outra metade é ligada ao iwai (roça), responsável pela plantação. Essas atividades se alternam anualmente; assim, os que estão ligados ao metare passam para o iwai no ano seguinte, e vice-versa. Todos os indivíduos possuem compromissos com a sua metade, quer seja caçar, roçar ou confeccionar ferramentas e adornos. A divisão temporal e de funções determina toda a vida social, desde a produção de alimentos às festas e rituais, permitindo que todos estejam preparados para o iwai ou o metare.

No período de metare, o clã, simbolicamente, reforça a identidade de se fazer longas caminhadas, o prazer das excursões de caça e pesca, bem como o respeito aos alimentos ofertados pela natureza. Durante o metare, ocorre a prática de jogos e excursões exploratórias; nos trajetos, que podem demorar dias, muitas redes são armadas entre as árvores - elas servem, além de descanso, para os momentos de concentração e reflexão, pausas nas quais os mais velhos transmitem aos mais jovens a sabedoria cosmológica Paiter. No metare, as mulheres (waled) confeccionam peças de cerâmica, colares e cestarias, e fiam e tecem tipoias utilizadas para transportar as crianças de colo; também tecem os gossypium, espécies de cintos e colares de algodão. Toda a produção artesanal feita durante o metare tem como destino presentear os Paiter que estiveram no iwai no final do Mapimaí.

Por sua vez o iwai é o momento de abnegação e introspecção; nesse periodo, se dedica mais tempo à produção de roças maiores, com vistas à "oferta" a toda comunidade. Cabe aos iwai a sagrada função de plantar, colher e cozinhar.

O Mapimaí é o momento de intersecção. Durante a festividade, ocorre a troca entre as metades, ou seja, os iwai, a partir do festejo, tornam-se metare, e os metare tornam-se iwai. Os iwai, como são responsáveis pela roça, ocupam a posição de anfitriões do Mapimaí. $\mathrm{O}$ auge da celebração ocorre quando os iwai ofertam a chicha aos convidados. A chicha, criada pelo herói mítico fundador "Palob", é uma bebida fermentada de mandioca e possui teor alcoólico; durante o 
festejo, tem a função de ser um purificador espiritual.

Toda ritualística que envolve o Mapimai é simbólica, carregada de significados para os Paiter. O líder cerimonial e sua esposa conduzem os membros dos clãs convidados em direção ao clã anfitrião. Cabe à mulher do líder conduzir uma tocha; o fogo, que foi um presente de Palob, representa o livre-arbítrio dos seres terrenos nos tempos da criação. Palob criou os seres humanos, dando-lhes liberdade para traçar seu próprio destino, para decidir entre o bem ou o mal. A tocha não pode ser apagada em momento algum do trajeto. Caso a chama se apague, é um prenúncio de tempos dificeis, de que Palob se recusará a visitar e proteger a aldeia. A tocha é deixada, cuidadosamente, dentro da maloca do líder cerimonial, para que seu fogo sagrado se extinga.

O líder anfitrião é eleito pelos chefes dos clãs convidados com base no seu prestígio e no conhecimento das tradições. Como na cosmologia Paiter tudo na vida se renova, durante o próprio evento se elege o próximo líder anfitrião, seguindo os critérios de credibilidade entre os membros da comunidade e sua sabedoria ancestral.

No Mapimaí, todos os membros da comunidade são convidados a participar. Desde os preparativos até a celebração da festa, cada indivíduo tem função e trabalho tradicionalmente estabelecidos, divididos socialmente por gênero e idade. Cabe aos homens adultos fazer arcos, flechas, enfeites de plumas, cocares e caçar os alimentos que serão servidos. Também é função masculina escolher o lugar da roça e, posteriormente, derrubar a mata, preparar o solo e fazer o plantio. Por sua vez, cabe às mulheres a confecção dos artesanatos, como colares, cerâmicas, anéis e a tecelagem de tipoias; elas também preparam os alimentos e são responsáveis, junto aos homens, por fazer a colheita.

O Mapimai apresenta-se, portanto, como um exemplo para compreender a divisão social do trabalho na sociedade Paiter Suruí pré-capitalista. Ainda dentro dessa compreensão, etnologicamente, é importante destacar o trabalho da pesquisadora Betty Mindlin, especialmente sua obra pioneira Nós, Paiter - Os Suruí de Rondônia (1985). Dentre outras questões, a autora trata das similitudes entre os Suruí, os Gavião, os Cinta Larga e os Zoró, que não apenas falam línguas do mesmo tronco (Tupi) e da mesma família (Mondé), como 
também compartilham de "traços culturais e mitologia parecida". Ao indagar-se "De onde teriam vindo?", Mindlin considera que "a história está menos nos fatos do que num relato mítico do universo" (1985, p. 25). A constatação teórica tem servido de orientação acadêmica para compreender o imbricamento entre o discurso mítico e a história do povo Paiter; a cosmologia é, portanto, intermediária da temporalidade e da dimensão constitutiva da realidade social. Ao estabelecer a relação dicotômica entre fato e relato mítico sob o prisma da historicidade, conecta o pensamento mítico à metáfora, sepultando a ilusão preconceituosa do "primitivo sem história". Assim, o discurso mítico explica ao não índio (ou ao de fora da aldeia) a relação dos Paiter com o mundo e entre si, dentro de uma referência à história do povo Paiter.

\section{O trabalho familiar}

José dos Santos, ao estudar um núcleo colonial camponês produtor de vinho no interior do Rio Grande do Sul, demonstrou, sociologicamente, que o trabalho familiar rural, pré-capitalista, se caracterizou por estabelecer relações produtivas baseadas na reciprocidade das obrigações interpessoais, e não nas relações salariais, uma vez que o trabalho era compreendido como elemento da reprodução social familiar/comunitária e não visava à acumulação de capital. Ainda segundo o autor, o trabalho comunitário tinha um caráter não capitalista, mesmo que os colonos estivessem subordinados ao modo de produção capitalista como "produtores simples de mercadorias" (SANTOS, 1984).

Para Georg Simmel (2006), nas sociedades pré-monetárias, a estruturação familiar e clânica é fundamental na determinação da forma que assumirá a divisão social do trabalho, estabelecendo culturalmente a divisão sexual das tarefas. Simmel (2006) e Weber (1991) informam que em todas as sociedades conhecidas, independentemente se matriarcais ou patriarcais, os seres humanos se categorizavam entre si através da distinção biológica do sexo, ou seja, entre masculino e feminino; com base nesta distinção, as crenças culturais, cosmovisões, normativas e tradições indicam quais status os homens e as mulheres deveriam ocupar e quais papeis deveriam desempenhar. Com base nas leituras 
de Weber (1991) e Bourdieu (1983), compreendemos status como simbólico determinado e inerente ao grupamento social, permitindo que $\mathrm{o}(\mathrm{s})$ indivíduo(s) desfrute $(\mathrm{m})$ de certo nível de prestígio, consideração e honra (BOURDIEU, 1983).

Fonte imprescindivel para compreender a sociedade pré-monetária Paiter é o uso das memórias dos anciãos. Para este trabalho, contamos com a entrevista do cacique Joaquim Suruí, da aldeia Gabgir, linha 14 da Terra Indigena Sete de Setembro. Roger Chartier (2007) nos orienta que a história se fundamenta sobre um saber universal socialmente pactuado; contudo, para a memória, a presença do passado no presente articula as narrativas das experiências vividas como forma de orientar o presente pretendido. Isso não significa que a história e a memória não possam se relacionar ou que a memória narrada e a história não possuam aproximações. Logo, a memória torna-se ponto de inflexão entre tempo, espaço e sujeito histórico, portanto, lugar privilegiado para examinar as múltiplas dimensões e relações entre o passado vivido e a história.

Perguntamos ao cacique Joaquim Suruí como era a divisão do trabalho na aldeia, especialmente antes do contato, e se homens e mulheres faziam as mesmas tarefas. Sobre o trabalho feminino, o cacique rememora:

Mulheres não se envolviam no trabalho de homens, mulheres tinham seu próprio trabalho. Homem fazia roça e depois queimava a roça e couvava, plantava na roça. Trabalho das mulheres era ir com homem carregar cará, mandioca, milho; mulheres tinham como seu trabalho fazer comida, chicha, mulheres não faziam trabalho de homem, ele só pegava lenha para ela fazer chicha. Trabalho de mulheres era socar milho no pilão para fazer chicha, mulheres têm seu trabalho diferente, fazer artesanato. (Entrevista realizada em 18/11/2019)

Já sobre o trabalho masculino, o cacique relata:

Homem tem seu trabalho, como caçar, pescar, construir casa, barracão. Trabalho de mulheres é varrer casa, limpar tudo para ficar limpo. Ela faz também panela de argila. Homem não faz panela, só busca lenha para 
mulher queimar a panela pra ficar pronta pra ser usada. Mulheres vão com homens na roça e vêm carregadas de cará. Mulheres cozinham a caça que homem foi buscar, homem busca lenha pra mulheres cozinhar. Mulheres dão a bebida para convidados do marido. Esses são trabalhos do homem, buscar caça e construir casa, as mulheres preparam comida e servem, limpam a casa, cuidam da família. (Entrevista realizada em 18/11/2019)

As memórias do cacique Joaquim Suruí nos orientam que as relações sociais de produção, social e culturalmente definidas, se valiam da distinção sexual do trabalho, atribuindo papéis sociais que eram incorporados por homens e mulheres Paiter. O trabalho feminino era compreendido como trabalho doméstico, auxiliar ao trabalho masculino.

Além da divisão social do trabalho, as memórias do cacique nos apontam para uma vivência mais coletiva, colaborativa e solidária entre os Suruí antes do contato. Se no mundo ocidental as premissas socioculturais têm como pilares a exaltação do indivíduo, o ideal do liberalismo e a racionalidade científica, o modo de vida Suruí baseavase numa sociedade coletiva. Para Simmel (1967), nas sociedades prémonetárias, o indivíduo dependia diretamente da coletividade para sua existência; após a monetarização, os indivíduos passaram a exercer cada vez mais o individualismo, marcado por uma lógica relacional de compra e venda do tempo, das relações sociais e do trabalho. Perguntamos ao cacique sobre as atividades produtivas desenvolvidas pelos Suruí antes do contato, suas estratégias de produção e a partilha dos recursos.

Quando homem ia caçar, ao matar o porcão, a mulher cozinhava, o homem chamava os convidados, colocava a caça em cima da esteira e o homem dividia para os convidados, ninguém podia ficar sem receber. Se o caçador não oferecia, a pessoa ficava magoada, até ficava triste. Para isso não acontecer, os Paiter dividiam os alimentos igualmente. Antigamente, ninguém podia desfazer do outro, todos eram unidos, solidários uns com os outros, tudo era fácil de viver harmoniosamente. Quando uma pessoa não ia com sua cara, a pessoa falava "você não está certo, você está desconfiado, se tornando mal, ruim". Antigamente, as pessoas viviam em harmonia, a comida dividia igualmente entre as pessoas do grupo.

Ainda mais o chefe, chamava as pessoas que viviam 


\begin{abstract}
por perto dele, chamava gritando os vizinhos deles para tomar chicha cedo, porque as pessoas tomavam a chicha cedo, como se fosse tomar café da manhã; isso também acontecia à noite, quando comiam carne de porcão. Mesmo a pessoa dormindo, acordava ela pra dar carne pra ela, senão ela ficava magoada se não acordassem ela para comer carne. Todos se juntavam no mesmo lugar, não sei hoje por que ninguém divide mais a caça, ninguém divide mais os alimentos para os parentes. (Entrevista realizada em 18/11/2019)
\end{abstract}

A caça talvez seja a principal atividade de exploração de recursos naturais feita pelo homem. A atividade de caça remonta a tempos imemoriais: existem registros de caçadores, suas táticas e tipos de caçadas desde a pré-história; nas florestas tropicais da América de Sul, estima-se que a caça seja praticada há mais de dez mil anos (FERRARI, 2001). Ainda hoje, é possivel afirmar que, para algumas comunidades, a caça continua sendo uma importante fonte de alimentos, tal qual era para os nossos antepassados (ALLEGRETTI, 1994).

Mesmo no século XXI, na Amazônia, caçar é fundamental para os povos da floresta devido ao isolamento, aos custos e à dificuldade de acesso a produtos e bens de consumo. Para muitas comunidades, a carne de caça é uma das poucas fontes de proteína e gordura animal disponiveis (AYRES, J. M.; AYRES, Cristina, 1979). Estudos no campo da nutrição informam que o teor de proteína contido nas carnes de caça é maior que o de todos os outros alimentos costumeiramente consumidos pelos povos da floresta (IORI; SANTOS, 2015).

Além do fator nutricional, a carne de caça representa, ainda hoje, uma importante atividade econômica para as comunidades rurais amazônicas. Já o consumo da caça também está conectado a atividades socioculturais. Dentre os povos indígenas, a prática da caça, bem como a feitura da carne, são conhecimentos transmitidos por gerações. A divisão da caça com os membros da comunidade é carregada de identitarismo; ademais, a figura do caçador goza de prestígio dentro da aldeia.

Com o avanço da frente pioneira e o aprofundamento das relações capitalistas, os Paiter Suruí se depararam com um processo de precificação da vida: tudo passou a ter um valor monetário. Até mesmo a natureza passou a ter, no universo de significados dos Suruí, valor 
econômico, afrouxando os laços de solidariedade. A partilha da caça e da coleta foi substituída pela venda. O cacique Joaquim Suruí lamenta esse novo contexto:

Hoje as pessoas cobram por um produto ao parente, uma caça ou semente de alguma coisa. Hoje queremos ser como homem branco, por isso que estamos acabando. Quando pede alguma coisa e outro não tem dinheiro, ele não compra, então. A regra antigamente era, quando uma pessoa pedia, dava. Mas hoje imitamos homem branco. A gente não vive como era antes, quando cobra e, quando não tem dinheiro, não compra. Não é da nossa cultura comprar as coisas do nosso próprio parente. (Entrevista realizada em $18 / 11 / 2019)$

Segundo Simmel (1967), o processo de monetarização enfraquece os laços de solidariedade que uniam os indivíduos aos seus grupos de pertencimento nas sociedades tradicionais. Com a economia monetária, os Paiter passaram a viver em uma espécie de fronteira simbólicosocial, dividindo seu mundo entre o mundo tradicional (pré-monetário e solidário) e o novo, capitalista (monetário e individualista); nessa fronteira, os laços de solidariedades, as noções de integrações, a identificação com suas raízes e até mesmo as diretrizes de direitos e vínculos comunitários têm sido substituídos, alterados e redefinidos.

É possivel identificar um ponto de intersecção entre Simmel (1967) e Marx (1991): para ambos, a modernidade intensificou a experiência da alienação na relação dos indivíduos, tanto entre si como com os objetos. Essa experiência é marcada pela coisificação e pela precificação; logo, na fronteira entre o tradicional e o moderno em que os Paiter passaram a viver na era pós-contato, a carne de caça não foi mais compreendida como alimento, mas como mercadoria. Nessa lógica, tudo passou a ter preço na dimensão econômica e social, instalando conflitos geracionais e mal-estar no mundo Paiter.

Não sei hoje. Antigamente as pessoas não trocavam, elas davam quando uma pessoa não tinha semente de alguma coisa; outro, quando tinha, dava pro outro. As pessoas só agradeciam a semente de milho dada pelo parente. Quando uma pessoa não tinha semente de milho, quando 
tinha outra, dava e não trocava somente, dava. Todos eram unidos e não faziam mal ao outro, mas se alguém fizesse mal ao outro, ele ficava magoado, doía nele. Por isso as pessoas davam quando pediam semente de alguma coisa, as pessoas não negavam nada uns aos outros. (Entrevista realizada em 18/11/2019)

A incidência da monetarização sobre a cultura é uma característica inerente à modernidade. Deste modo, segundo Simmel (1967), ela se presta à alienação das relações, pois transforma a economia monetária em orientação nas relações do mundo e faz com que o humano seja objetificado e impersonalizado; o indivíduo sente-se abandonado, na medida em que o dinheiro substitui os laços de solidariedade. Assim, a modernidade, alimentada pela monetarização da vida, cria as condições para o enraizamento de suas características: individualidade, racionalidade e calculabilidade, que se sobrepõem às dimensões de afeto, coletividade e solidariedade, essenciais para a sobrevivência do individuo nas sociedades tradicionais.

Outro aspecto da vida dos Paiter abalado pela incidência da monetarização foi a sedentarização. Os Paiter Suruí se constituíam com um povo seminômade, isto é, de migração sazonal. Afeitos às longas caminhadas, as mudanças periódicas de residência ocorriam nos limites do território tradicional; os Paiter não permaneciam mais que cinco anos na mesma área.

Nós vivia assim, não tinha aldeia permanente. Era quase nômades, abria uma aldeia e ficava no máximo cinco ou três anos naquele lugar, depois mudava de novo e ficava três ou quatro meses naquele local que escolheu, depois mudava novamente, ficava um ano. Vivia andando de lugar em lugar na floresta, mais que guerreava entre outra etnia como Cinta Larga e outros, depois voltava novamente no lugar, lider escolhia o lugar onde iam ficar, cacique escolhia, outras pessoas só esperavam a ordem do líder pra fazer alguma coisa, esperavam o tempo certo de agir. No tempo da chuva, eles escolhiam um pra ficar ali. Eles caçavam e dividiam entre eles, outro matava a caça para o líder. Aí no tempo da seca, o líder escolhia outro lugar que já tinha [sido] ocupado pelos outros na outra época, esfregava o chão com o pé pra ver se a terra já tinha usado, ia na frente esfregando o chão com o pé procurando a terra 
boa pra roçado, para plantio. Terra boa era terra preta e avermelhada, já usada pelos antepassados deles. Aí eles ficavam naquele lugar, pra ficar e abrir roçado ali. O líder pedia outro fazer dele em volta da casa dele, chefe que organizava a aldeia. (Entrevista realizada em 18/11/2019).

Além da roça tradicional, marcada por uma produção de subsistência, os Paiter dependiam da caça e da coleta para sua sobrevivência. Em sua estratégia de caçadores-coletores, se dividiam em pequenos agrupamentos, separados por grandes distâncias; toda caça e coleta não consumida era armazenada e, solidariamente, dividida nos tempos de escassez.

Os Paiter dividiam sim os alimentos. Exemplo, patuá. Um Paiter buscava e fazia suco, depois oferecia pro outro; mulher fazia suco e depois dividia o suco. Isso acontecia cedo, homem ia no mato buscar fruta e dividia entre os vizinhos e com quem estava por perto da casa. As pessoas dividiam mesmo a comida, não deixavam ninguém sem a fruta ou a caça. Quando homem buscava o mel, ao chegar na aldeia, dividia entre os parentes, fazia suco cedo e dividia. Isso acontecia mais entre cunhando, sogro, primo e filhos, as pessoas dividiam qualquer alimento que buscava no mato, exemplo: patuá, ingá, mirandiba, mel, castanha, ninguém podia ficar sem o alimento. (Entrevista realizada por Bruno Surui em 18/11/2019)

No mundo Paiter pós-contato, com a incidência da monetarização, o modelo de agricultura e moradia sazonal foi gradativamente substituído pela sedentarização das aldeias e de sua produção agrícola. Em poucos anos, o índio foi incorporando novas relações de trabalho, transformando-se em produtor, vaqueiro e criador. Como exemplo dessa transformação, os Paiter produziram 1,6 mil sacas de café na safra de 2019; o cultivo envolveu 110 famílias distribuídas por 15 aldeias da Terra Indígena Sete de Setembro. Destaca-se que o cultivo do café Paiter é baseado na agricultura familiar, e não se utilizam agrotóxicos em seus cafezais. A produção do tipo café robusto (Coffea canephora) atingiu os padrões de excelência exigidos no mercado internacional: as sacas foram exportadas a preço médio de $\mathrm{R} \$ 700,00$, valor três vezes maior que o preço médio da saca dos outros produtores em Rondônia (FUNAI, 2019). 
O avanço das frentes pioneiras e capitalistas - nas décadas de 1970-1990 - marcou as comunidades indígenas de Rondônia. Os encontros e desencontros entre colonos e indígenas envolveram diversos atores, tais como os agentes do Estado, a exemplo de funcionários públicos do INCRA, da FUNAI e policiais - como também posseiros, fazendeiros, garimpeiros e madeireiros. Betty Mindlin (1985) relatou que, em meados dos anos 1980, existiam apenas duas aldeias Paiter Suruí, distantes aproximadamente 50 quilômetros do município de Cacoal. Essa proximidade permitiu um intenso relacionamento entre os atores da colonização e os indígenas; segundo Mindlin, o avanço da fronteira agrícola tratava-se de "um dos casos mais flagrantes do choque da vida tribal com a fronteira econômica em expansão, com a ocupação empresarial e a devastação da Amazônia, com a explosão demográfica do novo estado de Rondônia" (MINDLIN, 1985, p. 15). Neste contexto, o cacique Joaquim relembra a criação de sua aldeia:

Quando abriu a aldeia resolvi construir umas casas para cada família com o dinheiro da extrair a madeira, porque um funcionário da Funai pediu que os Paiter tirassem as madeiras, mas os indígenas não sabiam como que era isso, tirar madeira, mas o funcionário dizia para os Paiter, prometendo melhorar a vida deles, eles não sabiam o que era isso, só perceberam quando os não indígenas entraram com máquinas como trator caminhão, até então nunca vistos. Quem estava fazendo isso era funcionário da Funai, eles roubaram muito o dinheiro. Eu não sabia de metro ou cúbico de madeira. Foi tirada muita madeira, aí percebi, vi coisa e decidi construir mais casa, eu pegava dinheiro e distribuía para comunidade. O Paiter era organizado, comprava mercadoria e distribuía para todos, eram 15 famílias. Quando a construção das casas terminou trouxe energia movida a motor, aldeia ficava iluminada. Quando terminou a construção da aldeia, fizeram inauguração, compraram mercadoria, refrigerantes, carnes, todas as aldeias foram convidadas. Os madeireiros fizeram poços para comunidade beber água, aí a aldeia estava completa, com energia, tudo iluminado. (Entrevista realizada em $18 / 11 / 2019)$

A história de Rondônia e dos Paiter Suruí se confundem; a vida de seus atores foi marcada por relações de disputa, conflitos e negociações. À medida que se intensificava o contato com os não índios, 
a economia tradicional dos Paiter Suruí passou a ser influenciada pelos modos de vida da cultura que se apresentava. Com a vinda dos colonos e as sucessivas invasões ao território indígena, os Paiter passaram a sofrer o aliciamento de madeireiros. A exploração madeireira, aliada à ameaça de invasão da TI Sete de Setembro, promoveu a desagregação das famílias Paiter.

Antes do contato, os Paiter Suruí baseavam-se em duas grandes aldeias. O aliciamento dos madeireiros e a constante ameaça ao território, por meio das invasões, estabeleceu uma nova lógica econômica e de ocupação do território, marcada pela mobilidade populacional. Nathália Silva e José Neto (2014) defendem a tese que os Paiter Suruí passaram a se dispersar pelo território e a criar novas aldeias, pois perceberam que a ocupação dos espaços não explorados possibilitava acordos comerciais entre os indígenas e os madeireiros. No universo cosmológico dos Suruí, a natureza passou a ter valor monetário, especialmente pela venda de madeira. Nesse período, a habitação provisória das malocas foi sendo substituída por moradias permanentes com as casas de madeira, ressignificando as relações tradicionais Paiter com o espaço.

\section{Conclusão}

O processo de monetarização da vida social dos Paiter Suruí não significou a descaracterização deste povo como genuinamente indígena; este estudo tampouco teve como premissa ser uma espécie de advocacia do "bom selvagem" rousseauniano. O avanço das relações capitalistas significou novas formas de racionalidade e sociabilidade entre os Paiter Suruí. Entre as diversas lógicas e práticas (res)significadas pela chegada do dinheiro na vida dos indígenas, observou-se a reprodução da lógica de mercado no interior das aldeias. Entretanto, enquanto a modernidade fomenta o individualismo, a sociabilidade tradicional dos Paiter remete à coesão social. Nos encontros e desencontros entre o moderno e a tradição, existe espaço dentro da aldeia para a roça de subsistência, como também para apropriação de tecnologias no cultivo do café. É na aldeia que se integram, interagem e coexistem sociabilidades: ao mesmo tempo que os Suruí fazem perfis nas redes sociais, eles pintam o corpo para 
se proteger das doenças. O uso da internet não deslegitima as práticas da tradição, "da vida no mato", expressas na língua, materializadas no artesanato e vivenciadas nas festas tradicionais. A monetarização da vida social dos Paiter Suruí foi - e ainda é - um fenômeno marcado pela contradição e que evidencia o quanto a história é dialética.

\section{Referências}

ALLEGRETTI, M. Reservas extrativistas: parâmetros para uma política de desenvolvimento sustentável na Amazônia. In: ANDERSON, Anthony et al. (Eds.). O destino da floresta: reservas extrativistas e desenvolvimento sustentável na Amazônia. Rio de Janeiro: Relume-Dumará, 1994.

AYRES, J. M.; AYRES, Cristina. Aspectos da caça no alto rio Aripuanã. Acta Amaz., Manaus , v. 9, n. 2, p. 287-98, jun. 1979.

BOURDIEU, P. Questões de sociologia. Rio de Janeiro: Marco Zero, 1983.

CHARTIER, R. A história ou a leitura do tempo. Belo Horizonte: Autêntica, 2007.

ENGELS, Friedrich. Sobre o papel do trabalho na transformação do macaco em homem [1876]. In: MARX, Karl; ENGELS, Friedrich. Textos 1. São Paulo: Edições Sociais, 1977.

FERRARI, S. F. A fauna de mamíferos não-voadores da Reserva Biológica do Traçadal-RO. Relatório Técnico. Porto Velho: ONG Kanindé, 2001.

FUNAI, 2019. Abril Indigena: produção de café especial do Povo Suruí Paiter pode crescer até $60 \%$ em 2019. Disponivel em: http://www. funai.gov.br/index.php/comunicacao/noticias/5346-povo-suruipaiter-producao-de-cafe-especial-pode-crescer-ate-60-em-2019. Acesso em: 2 ago. 2020.

IORI, Marlon Marcel; SANTOS, Christian Fausto Moraes dos. A carne, a gordura e os ovos: colonização, caça e pesca na Amazônia. Porto Alegre: EDIPUCRS, 2015. 
MARX, Karl. O Capital. Livro I. Rio de Janeiro: Civilização Brasileira, 1991.

MINDLIN, Betty. Nós Paiter — Os Suruí de Rondônia. Petrópolis: Vozes, 1985.

SIMMEL, G. A metrópole e a vida mental. In: VELHO, Otávio Guilherme (Org.). O fenômeno urbano. Rio de Janeiro: Zahar, 1967.

SILVA, Nathália Thaís Cosmo da; NETO, José Ambrósio Ferreira. A monetarização da vida social dos Paiter Suruí Bol. Mus. Para. Emílio Goeldi. Cienc. Hum., Belém, v. 9, n. 1, p. 163-181, jan.-abr. 2014

SIMMEL, Georg. Questões fundamentais da sociologia: indivíduo e sociedade. Rio de Janeiro: Zahar, 2006.

WEBER, Max. Economia e sociedade: fundamentos da sociologia compreensiva. Brasília: Editora da UnB, 1991. 